This PDF is a selection from an out-of-print volume from the National Bureau of Economic Research

Volume Title: The Rate and Direction of Inventive Activity: Economic and Social Factors

Volume Author/Editor: Universities-National Bureau Committee for Economic Research, Committee on Economic Growth of the Social Science Research Council

Volume Publisher: Princeton University Press

Volume ISBN: 0-87014-304-2

Volume URL: http://www.nber.org/books/univ62-1

Publication Date: 1962

Chapter Title: Some Difficulties in Measuring Inventive Activity

Chapter Author: Barkev S. Sanders

Chapter URL: http://www.nber.org/chapters/c2113

Chapter pages in book: (p. 53 - 90) 


\title{
Some Difficulties in Measuring Inventive Activity
}

\author{
BARKEV S. SANDERS \\ THE PATENT, TRADEMARK, AND COPYRIGHT FOUNDATION \\ OF GEORGE WASHINGTON UNIVERSITY
}

THIS paper is directed toward exploring some of the difficulties in measuring the rate of inventive activity. First, I examine the problems involved in trying to measure inventive activity through readily available information on inputs. Then I turn to the attempts to measure this variable through the rate of technological progress. Finally, I examine the use of patent statistics as a possible measure of inventiveness. The conclusions reached are negative. In my opinion none of the measures used to date is satisfactory even as a crude measure of inventiveness as such or inventive activity.

\section{Measuring the Rate of Invention Through Input}

Economists analyze input in terms of various factors of production, i.e., labor, capital and land. These have their respective units of measurement, units which we may regard as roughly uniform. To determine the degree of association between the input for inventions and the resulting inventions we must either (1) have some means to quantify inventions to test the association empirically, or (2) by definition agree to accept input as a measure of inventive activity, reconciling ourselves to the fact that this may be the closest approximation possible, or (3) develop some acceptable theory of inventions which can explain the nature and extent of the association between input and the end product which is invention.

However, there appears to be no commonly accepted unit of measurement for inventions, despite the fact that in many discourses on the subject one often encounters phrases implying that it is possible to quantify inventions by their number. Thus, in the Encyclopaedia Britannica, it is said:

Many lists of the "world's greatest inventions" have been prepared, all widely different. The following list of seven has no unusual authority but is perhaps defensible. ${ }^{1}$

The list includes: (1) discovery of seeds and plants; (2) control of fire; (3) invention of pottery; (4) invention of writing; (5) invention

1 "Inventions and Discoveries," Encyclopaedia Britannica, Vol. 12, 1949, p. 545. 
of standards of measurement, i.e. weights, time, money; (6) the germ theory; and (7) tinned food. It may be noted that by and large these are not patentable inventions under the Patent Laws of the United States. More important, the way in which these inventions are considered makes it clear that they can not be regarded as equivalent units. Furthermore, since they are labeled as the most "important" inventions, it follows that other inventions are not equivalent to these. With a concept of invention consistent with this notion, it is difficult to see how one can establish any meaningful relationship between the number of inventions, and some measure of input, in view of the disparate units descriptive of the former.

A recent sociological treatise states:

In the light of this principle of invention by combination, it becomes clear that the speed of cultural change depends upon five factors: (1) the number of culture elements from which new inventive combinations can be made; (2) the speed and completeness with which new inventions and discoveries are made known and made available to those who can make use of them; (3) the amount of improvement which each element is able to contribute; (4) the degree to which scientific methods are applied to the problems of cultural change; and (5) the intensity of the need or desire for the solution of various problems. ${ }^{2}$

The simple statement that the speed of inventions depends on the number of available cultural elements appears at first glance measurable, but as the author goes on to elaborate his views regarding the nature of these elements and the many facilitating factors which are deemed necessary so as to account for the present inventiveness, it becomes clear that such is not the case. If one were to adopt the theory elaborated by Hart as to what accounts for inventiveness, it is difficult to see how one could estimate the rate of inventions from the input, especially in the sense in which we are using that term here. Hart himself measures inventiveness in terms of its by-product, i.e. technological advance. In fact he seems to consider the two synonymous as we shall see when we consider the measurement of inventions or inventive activity in terms of output.

Despite the practical difficulties, one is led intuitively to believe that

${ }^{2}$ Francis R. Allen, Hornell Hart, Delbert C. Miller, William F. Ogburn, and Meyer F. Nimkoff, "Technology and Social Change," p. $49 \mathrm{ff}$. 
there has to be some direct causal relationship between input and the frequency and extent of inventions, no matter how one measures the latter. Our economy certainly operates on the belief that there is this causal link between the two. Thus, the United States Congress increases research expenditures for specific diseases with the conviction that ways will thus be found to prevent or cure such diseases. We clamor for increased expenditures for space research to catch up with the Russians. Companies facing production difficulties increase their outlays for research with reasonable assurance that they will thereby find ways to overcome their problems. Our most successful corporations today are those with the highest proportionate expenditures for research and development. ${ }^{3}$ Relatively higher " $R$ " and " $D$ " expenditures by chemical companies are believed to account for the increased proportion of chemical patents in relation to mechanical patents shown in Table 1.4

Intuitive relationships, however universally accepted, are not scientific proof of our ability to chart the course of inventions from the measurement of inputs. Empirical evidence of some apparent acceleration of inventions with increased input gives us no quantitative measure of the extent of this association or of the degree of acceleration in inventions with a specific increase in input; neither does it yield any clues as to the invariance of the functional relationship between input and the resulting inventions at different times. ${ }^{5}$ No doubt there is a direct relationship of some kind, but we have no evidence that this relationship does not change. To measure inventions from input we need to know this. We need a much clearer understanding of the nature of inventive activity and a better perception of the intermediate steps linking inventive input with inventive output in different types of activities and at different times, before we can hope to measure or foretell the trends in invention or inventiveness from the measurement of relevant inputs. What we need most at this time is more

\footnotetext{
${ }^{3}$ Herbert Solow, "The Medicine Men of Kalamazoo," Fortune, July 1959, pp. 107-112, 164-168.

4 Science and Engineering in American Industry, Final Report on a 1953-1954 Survey, National Science Foundation 56-16, Washington, 1956, especially pp. 21-28. Proceedings of a Conference on Research and Development and its Impact on the Economy, NSF 58-36, Washington, especially, Ralph E. Burgess, "Impact of Research and Development in the Chemical Industry," pp. 55-67.

${ }^{8}$ Even though it would be reasonable to assume that an increase in input would always mean some increase in inventive output at a given time, $t_{0}$, this does not mean that the identical increment in input at a later time, $t_{1}$, will have an increase equal to that produced at $t_{0}$.
} 


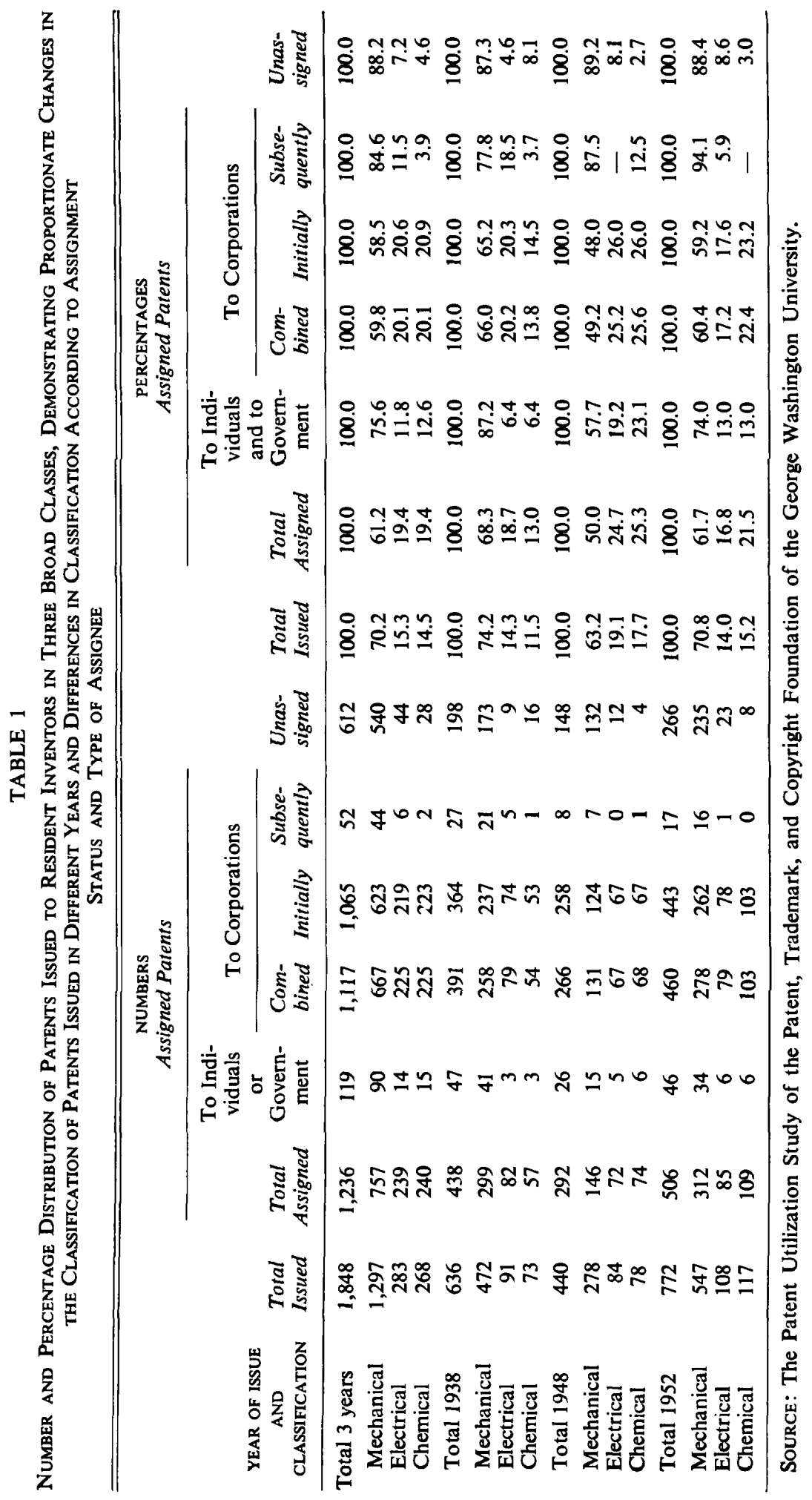


verifiable facts about the nature of invention and the factors which appear to inhibit or accelerate it.

So far we have considered whether we can determine the rate of inventions from the measurement of inputs. We have gone on the assumption that we are able to measure inputs in homogeneous and uniform units. But this assumption is not justified. We not only have no way to quantify the dependent variable (inventions), but we are far from having any precise measure of the independent variable (input) which is to be used as our yardstick. For instance, there is no satisfactory measure of over-all labor input for inventive activity. There is every reason to believe that over the decades the number of persons who give a considerable fraction of their time to inventive activity has increased; but what the rate of this increase has been we can not say. Even today, not all persons who produce inventions devote all, or perhaps even a major part of their working time, to inventing. Apparently, some inventions are still made by persons who give very little time to inventing, as such. We have practically no information on the number of persons in our population who have made inventions, and how much time they have given to inventing. It is astounding how incomplete our factual information is in these matters.

Productivity of labor in inventing depends on the technical skills and training of such labor. We believe there has been a progressive upgrading of the educational level of inventors over the course of time. The educational level of inventors of patented inventions in the sample of patents studied by the Patent, Trademark, and Copyright Foundation of the George Washington University confirms this belief. It shows a higher educational level for inventors of patented inventions in 1952 in comparison with that of 1938 - a relatively short span of time. Since this is true for inventors of patented inventions, there is no reason to doubt it is true for inventors in general. Considering inventors of assigned patents in contrast to inventors of unassigned patents, the Foundation's Study shows very marked difference in the average educational level, in favor of inventors with assigned patents. ${ }^{6}$

\footnotetext{
${ }^{6}$ The educational level of inventors of assigned patents in the Patent Utilization Study is 16.0 and 16.7 years in terms of the mean and the median, respectively. The corresponding measures for inventors of unassigned patents are 12.3 and 12.5. It may be noted that according to the 1950 Census the average schooling for males age twenty-five and over in the United States was 9 years. For inventors see Barkev S. Sanders, "Patent Utilization," Patent, Trademark, and Copyright Journal, Conference Supplement, 1957, p. 74, and Table F on p. 155.
} 
We may assume that similar differences have prevailed all along between these two broad groups of inventors. Therefore, as the proportion of assigned patents has increased, signaling an increase in the number of inventors of assigned patents, there has been a parallel upgrading of the educational levels of inventors. ${ }^{7}$ In other words, even if we could by some agreed-upon formula approximate the aggregate man-hours spent on inventive activity, the progressive change in the qualitative characteristics of inventors, with respect to their educational levels and probably many other particulars as well, would still be an important factor to be taken into consideration in equating inputs over time. ${ }^{8}$

When we consider inputs in terms of capital, there can be no question but that the quality of the tools and equipment avilable for inventive activity has improved tremendously and is still improving. ${ }^{9} \mathrm{It}$ is also likely that the productivity of labor and capital inputs, so far as inventions are concerned, varies very markedly at different times and in different industries. It may be noteworthy in this connection that the National Science Foundation Study found little, if any, association between the number of patent applications pending and the expenditures in 1953 and 1954 for $R$ and $D$ reported by different industries. ${ }^{10}$

One does not overcome these shortcomings in the basic information on inputs for inventions or the qualitative changes in the labor and capital components, or the nonequivalent outputs for equivalent inputs in different industries, or changing functional relationship between input and invention over time, by shifting attention from specific factors of production to the annual expenditures for research and development or some related series that may serve as a common denominator. Such a shift, at best, camouflages the basic difficulties to which we have referred. The shift, in its turn, introduces the additional deficiencies inherent in the available expenditure series. Thus, the National Science Foundation series on research and development expenditures do not go very far back. More importantly, they are patently

${ }^{7}$ Ibid.

${ }^{8}$ The Patent Utilization Study shows that 90 to 95 per cent of assigned patents are developed by employees and the vast majority of such employees are required by contract to assign their inventions to the employer for patenting purpose. Barkev S. Sanders, Joseph Rossman, and James L. Harris, "Patent Acquisition by Corporations," Patent, Trademark, and Copyright Journal, Fall 1959, pp. 217-261.

${ }^{\theta}$ It should be noted that the training and selection of inventors itself involves capital outlays; in other words, the labor input which we consider is not free from some capital input, although the latter was not specifically allocated to inputs in invention.

${ }^{10}$ Science and Engineering in American Industry, Final Report on a 1953-1954 Survey, pp. 37-38. 
incomplete since they do not attempt to include individual effort in inventive activity. They are restricted entirely to expenditures by corporate bodies and government. The series preceding the NSF data was constructed retrospectively and is subject to wide margins of error. The use of annual expenditures for $R$ and $D$ does not take into consideration qualitative changes in capital and labor or shifts in the industries responsible for the expenditures reported. No one would contend that the contribution of individual inventors as against "corporate" inventors, or the contribution of inputs by corporations and government, or by different industries have remained relatively constant over time. Therefore, this shift remedies none of the difficulties enumerated earlier; it merely adds others. Under these circumstances, about the only thing we can assert is that the fraction of total expenditures made by corporate entities and government-the recorded portion-has been increasing; at what rate (in any real and invariant sense) we do not know.

As for the quality and the completeness of the monetary series, even for the corporate and governmental segments the estimates are subject to a wide margin of error. In all probability, both the magnitude and the direction of the errors have changed from year to year and certainly over long stretches of time. It would be reasonable to assume that for the earlier years, for which the series had to be constructed retrospectively, expenditures are understated while in more recent years the tendency is toward overstatement. Independent of the systematic errors in constructing the series for the earlier years, these estimates are subject to large errors at any given time. For corporate agencies the amounts reported are subject to many judgmental considerations for different companies, and even for the same company at different times. Moreover, as relatively large expenditures for research and development have gained prestige for reporting companies, the scope of what is considered $\mathrm{R}$ and $\mathrm{D}$ expenditure has expanded. Such an expansion in the scope of reported expenditures is particularly likely to have occurred as a result of the amendments to the 1954 Revenue Act, which excepts corporate expenditures for research and development from Federal taxation. ${ }^{11}$ It is notable that, only a fraction of the total amount spent for $\mathrm{R}$ and $\mathrm{D}$ is actually spent on inventions as such.

In view of these uncertainties, it should be obvious that even though

11 Internal Revenue Code of 1954, Sec. 1235. 
the evidence might be unequivocal that the amounts spent for inventions have increased, a large though unknown fraction of this increase is apparent rather than real. Aside from the large errors in the series of expenditures for $\mathrm{R}$ and $\mathrm{D}$, at no time have we known what fraction of the total has been spent for inventions specifically and at what rate this fractional amount has changed in relation to the total.

Still another difficulty inherent in any series based on monetary units is the elasticity of the units recorded. The elasticity of the dollar is univerally known. What is not widely known, or at least not appreciated, even by many economists, is that deflating the dollars spent by the Consumer Price Index does not completely compensate for this elasticity. ${ }^{12}$ In the case in point, the purchasing power of the dollar spent for personnel and equipment used specifically for inventions has changed at a rate different from the averages reflected in the Consumer Price Index..$^{13}$ We have, as of now, no appropriate deflation index as far as $R$ and $D$ expenditures are concerned. The National Science Foundation is acutely aware of this shortcoming. ${ }^{14}$

These basic limitations in both the dependent variable, inventions, and the independent variable, input for inventions (whether in terms of the actual factors of production or in terms of monetary outlays) cannot be overcome by the addition of other more or less associated variables to the monetary input so as to obtain a composite index, as has been tried. ${ }^{15}$ In terms of our available insights and information it seems of dubious value at this time to attempt to estimate the trend of inventions from the available series of inputs for invention. It would appear that over the recent decades there has been a progressive increase in the input for inventive activity. But with increased inputs there have been concomitant transformations, the effects of which on the functional relationship between input and inventions can not be appraised at this time. Since the beginning of this century inventive

\footnotetext{
${ }^{12}$ Barkev S. Sanders, "Local Health Departments, Growth or Illusion?" Public Health Reports, January 1959, pp. 13-20.

${ }^{13}$ Barkev S. Sanders, "Discussion on Structures, Uses and Inadequacies of the Official Price Deflators," Proceedings of the Business and Economic Statistics Section, American Statistical Association, 1959, pp. 320-322.

${ }^{14} \mathrm{It}$ is my understanding that at present the National Science Foundation is trying to develop an appropriate deflation index for $\mathbf{R}$ and $\mathbf{D}$ expenditures.

${ }^{15} \mathrm{I}$ have in mind here specifically the as yet unpublished study of my good friend, S. Colum Gilfillan, in which he attempts to estimate inventive effort by a composite index which includes among other things the professional staff for $R$ and $D$. The study was prepared for the Senate Subcommittee on Patents, Trademarks, and Copyrights of the Committee on the Judiciary of the United States Senate. Gilfillan has been generous enough to give me a copy of his manuscript to assist me in preparing the present paper, for which I am very grateful.
} 
activity has shifted progressively from individual effort to organized effort. Table 2 shows this clearly with respect to patented inventions in the United States. It should be noted that much of this transition occurred in the first quarter of this century; there has been little, if any, consistent trend since 1940. Expenditures for research have shifted more and more toward larger organizational units. The input has come more and more from large corporate sources and from the Federal Government. In the case of the latter especially there are various restraints on any resulting patent rights.

In the meantime, the character of inventions has been changing (as we have shown earlier in Table 1) in terms of patented inventions in the United States in recent years. The solo inventor, whether working for a corporation or for himself, has been progressively replaced by groups of inventors; a natural corollary to the explosive growth of scientific knowledge and the consequent need for specialization. ${ }^{16}$ What effects these and other changes have had on the productivity of input for inventions we do not know now. In the past very little attention has been given to the study and analysis of these relationships. The splitting up of knowledge through specialization in all probability reduces what we might call the conversion coefficient of input to invention, even if all other factors are held constant. It is quite possible that in terms of invention the productivity of the tax dollar is much lower than that of the corporation dollar, and the corporation dollar less productive than the dollar spent by individuals. Also, it is probable that the productivity of dollars spent for invention varies widely by industry and by the size of corporate entities, their organization and management patterns.

Moreover, we do not know whether or not there has been a progressive increase in the input requirement for inventions today, in comparison with inventions in the past. On the hypothesis that the more obvious and easily exploitable combinations of elements become exhausted, other things remaining equal, new inventions become more and more difficult, i.e. they require greater and greater input for a given volume of inventions, regardless of how we measure the latter. There is also the probability that in terms of factors of production, inputs of higher quality may be required, thus implying higher costs,

\footnotetext{
${ }^{18}$ The Patent Utilization Study shows that in 1938, 11 per cent of the assigned and 7 per cent of the unassigned patents had two or more inventors; in 1952, these percentages were 23 and 11 , respectively. This trend is in line with other evidence of a progressive increase in teamwork. See George P. Bush, and Lowell H. Hattery, "Teamwork in Research," 1953.
} 


\section{TABLE 2}

Number of Patents Issued to Corporations, Individuals, and to the United States Government, and the Proportion of Patents Issued to Cor porations Compared With That Issued to Individuals, 1901-1957

\begin{tabular}{|c|c|c|c|c|c|c|}
\hline \multirow[b]{2}{*}{$\begin{array}{l}\text { Year of } \\
\text { Issue }\end{array}$} & \multicolumn{4}{|c|}{ Number of Patents Issued } & \multicolumn{2}{|c|}{ Percentage } \\
\hline & Total $^{a}$ & Companies & $\begin{array}{l}\text { Indi- } \\
\text { viduals }\end{array}$ & $\begin{array}{c}\text { U.S. } \\
\text { Government }\end{array}$ & $\begin{array}{c}\text { To } \\
\text { Companies }\end{array}$ & $\begin{array}{c}\text { To Indi- } \\
\text { viduals }\end{array}$ \\
\hline $\begin{array}{l}1957 \\
1956\end{array}$ & $\begin{array}{l}42,744 \\
46,817\end{array}$ & $\begin{array}{l}26,627 \\
29,192\end{array}$ & $\begin{array}{l}15,154 \\
16,643\end{array}$ & $\begin{array}{l}963 \\
982\end{array}$ & $\begin{array}{l}62.3 \\
62.4\end{array}$ & $\begin{array}{l}35.5 \\
35.5\end{array}$ \\
\hline $\begin{array}{l}1955 \\
1954 \\
1953 \\
1952 \\
1951\end{array}$ & $\begin{array}{l}30,432 \\
33,809 \\
40,468 \\
43,616 \\
44,326\end{array}$ & $\begin{array}{l}17,828 \\
20,620 \\
23,524 \\
24,375 \\
24,468\end{array}$ & $\begin{array}{l}11,914 \\
12,531 \\
16,284 \\
18,538 \\
19,192\end{array}$ & $\begin{array}{l}689 \\
658 \\
658 \\
695 \\
659\end{array}$ & $\begin{array}{l}58.6 \\
61.0 \\
58.2 \\
55.5 \\
55.2\end{array}$ & $\begin{array}{l}39.1 \\
37.0 \\
40.2 \\
42.5 \\
42.8\end{array}$ \\
\hline $\begin{array}{l}1950 \\
1949 \\
1948 \\
1947 \\
1946\end{array}$ & $\begin{array}{l}43,040 \\
35,131 \\
23,963 \\
20,139 \\
21,803\end{array}$ & $\begin{array}{l}23,442 \\
19,663 \\
13,752 \\
12,117 \\
14,071\end{array}$ & $\begin{array}{r}18,960 \\
14,957 \\
9,812 \\
7,784 \\
7,444\end{array}$ & $\begin{array}{l}622 \\
485 \\
352 \\
155 \\
147\end{array}$ & $\begin{array}{l}54.5 \\
56.0 \\
57.4 \\
60.2 \\
64.3\end{array}$ & $\begin{array}{l}44.0 \\
42.6 \\
49.7 \\
38.7 \\
34.2\end{array}$ \\
\hline $\begin{array}{l}1945 \\
1944 \\
1943 \\
1942 \\
1941\end{array}$ & $\begin{array}{l}25,695 \\
28,053 \\
31,054 \\
38,449 \\
41,109\end{array}$ & $\begin{array}{l}16,245 \\
17,414 \\
18,546 \\
23,305 \\
24,744\end{array}$ & $\begin{array}{r}8,981 \\
9,636 \\
11,654 \\
14,534 \\
16,322\end{array}$ & $\begin{array}{r}87 \\
106 \\
48 \\
62 \\
43\end{array}$ & $\begin{array}{l}63.6 \\
62.2 \\
59.7 \\
60.7 \\
60.2\end{array}$ & $\begin{array}{l}35.0 \\
34.3 \\
37.5 \\
37.8 \\
39.7\end{array}$ \\
\hline $\begin{array}{l}1940 \\
1939 \\
1938 \\
1937 \\
1936\end{array}$ & $\begin{array}{l}42,238 \\
43,073 \\
38,061 \\
37,683 \\
39,782\end{array}$ & $\begin{array}{l}24,571 \\
24,440 \\
21,698 \\
21,655 \\
23,110\end{array}$ & $\begin{array}{l}17,624 \\
18,582 \\
16,303 \\
15,994 \\
16,639\end{array}$ & $\begin{array}{l}40 \\
50 \\
59 \\
33 \\
33\end{array}$ & $\begin{array}{l}58.2 \\
56.7 \\
57.0 \\
57.5 \\
58.1\end{array}$ & $\begin{array}{l}41.7 \\
43.2 \\
42.9 \\
42.4 \\
41.8\end{array}$ \\
\hline $\begin{array}{l}1935 \\
1934 \\
1933 \\
1932 \\
1931\end{array}$ & $\begin{array}{l}40,618 \\
44,420 \\
48,774 \\
53,458 \\
51,756\end{array}$ & $\begin{array}{l}22,839 \\
24,660 \\
26,010 \\
27,147 \\
25,110\end{array}$ & $\begin{array}{l}17,757 \\
19,731 \\
22,813 \\
26,274 \\
26,618\end{array}$ & $\begin{array}{l}22 \\
29 \\
51 \\
37 \\
28\end{array}$ & $\begin{array}{l}56.2 \\
55.5 \\
53.3 \\
50.8 \\
48.5\end{array}$ & $\begin{array}{l}43.7 \\
44.4 \\
46.6 \\
49.1 \\
51.4\end{array}$ \\
\hline $\begin{array}{l}1930 \\
1929 \\
1928 \\
1927 \\
1926\end{array}$ & $\begin{array}{l}45,226 \\
45,267 \\
42,357 \\
41,717 \\
44,733\end{array}$ & $\begin{array}{l}21,500 \\
19,900 \\
19,000 \\
16,300 \\
16,100\end{array}$ & $\begin{array}{l}23,726 \\
25,367 \\
23,357 \\
25,417 \\
28,633\end{array}$ & $\begin{array}{l}- \\
- \\
-\end{array}$ & $\begin{array}{l}47.6 \\
44.0 \\
44.9 \\
39.1 \\
36.0\end{array}$ & $\begin{array}{l}52.4 \\
56.0 \\
55.1 \\
60.9 \\
64.0\end{array}$ \\
\hline $\begin{array}{l}1925 \\
1924 \\
1923 \\
1922 \\
1921\end{array}$ & $\begin{array}{l}46,432 \\
42,574 \\
38,616 \\
38,369 \\
37,798\end{array}$ & $\begin{array}{l}16,100 \\
13,400 \\
11,600 \\
11,000 \\
10,700\end{array}$ & $\begin{array}{l}30,332 \\
29,174 \\
27,016 \\
27,369 \\
27,098\end{array}$ & $\begin{array}{l}- \\
- \\
-\end{array}$ & $\begin{array}{l}34.7 \\
31.5 \\
30.0 \\
28.7 \\
28.3\end{array}$ & $\begin{array}{l}65.3 \\
68.5 \\
70.0 \\
71.3 \\
71.7\end{array}$ \\
\hline 1916 & 43,892 & 12,150 & 31,742 & - & 27.7 & 72.3 \\
\hline 1911 & 32,856 & 8,100 & 24,756 & - & 24.7 & 75.3 \\
\hline 1906 & 31,170 & 6,420 & 24,750 & - & 20.5 & 79.5 \\
\hline 1901 & 25,546 & 4,650 & 20,896 & - & 18.2 & 81.8 \\
\hline
\end{tabular}

SOURCE: Historical Statistics of the United States, Revised Edition, 1960, Chap. W, Series W 66-75, p. 599.

a We have used the basic figures as published even though they are not always internally consistent. The differences are negligible, however. The percentages have been computed. 
even though this may not become apparent in terms of labor input as such.

When we top all of these uncertainties and difficulties with the perceptive difficulty as to what it is really that we are trying to measure, it should be evident that no sober student of this phenomenon will venture any firm opinion as to whether increases in input for inventions, signify proportionate increases in inventions over time.

We would like to see continued attention given to the compiling and improving of the quality of available information with respect to the national effort going into inventions. We believe that neither the quality nor the completeness of the information which we have now, nor our conceptual understanding of the functional relationship between input and inventions, are such as to enable us to determine from apparent trends in input the trends in inventions.

Ultimately, we may find that the only practical approximation to inventive activity is in terms of input for invention. There is all the more reason to try to purify this series and reduce the types of errors to which it is currently subject.

\section{Measuring the Rate of Invention Through the Rate of Technological Progress}

Instead of using input other students of invention have attempted to measure the rate of invention through technological changes, which they regard as the output of inventive activity.

The logic of measuring inventions in terms of technological progress, as the resultant of invention, is quite as justifiable as the attempt to measure it in terms of inputs. Both of these approaches are also in conformity with folk wisdom ${ }^{17}$ Both are used by science. Thus, in physical sciences it is not uncommon to measure some force, such as electricity, in terms of its effect, whether by the lighting of an incandescent lamp, the heating of an oven, or the output of a generator. However, these analogies are not quite valid; the transmutation of inventions into technological progress implies a series of intermediate steps which may not remain invariant over time. As my good friend Colum Gilfillan points out in his work for the Senate Subcommitte on Patents, Trademarks, and Copyrights:

\footnotetext{
${ }^{17}$ Thus the relationship between input and inventions is reflected in the Biblical axiom: "Whatsoever a man soweth, that shall he also reap." (Galatians, Ch. 6, Vs. 7). Notice, however, that this is not quantified. The relationship between invention and technological progress is reflected in the statement: "Ye shall know them by their fruits." (Matthew, Ch. 7, Vs. 16).
} 
Progress and productivity depend on many other things-the use and disuse of old inventions, the importation of foreign ones, innovations other than inventions, mistakes public or private, the supply of capital and land, the discovery or exhaustion of resources, the education and quality of labor. . . ${ }^{18}$

In connection with patented inventions, the present writer, while a graduate student at Columbia University, did extensive work in attempting to correlate patented inventions in specific industries with economic measures of productivity, but dropped the whole matter, being unimpressed with the coefficients of correlation obtained (after the removal of secular trends in relation to time). These coefficients of correlation seldom exceeded 0.3 or 0.4 , and literally thousands were computed. But even these relatively low coefficients were obtained after much trial and error with different lags and leads between the series that were being correlated. The question of how much of the apparent association was real, and how much accidental, allowed no great confidence to be placed in the end results. But even if one took the coefficients at their face value, they would be of little help in forecasting the dependent variable from a knowledge of the independent variable. ${ }^{19}$ Similar efforts by Jacob Schmookler were no more impressive in this respect. ${ }^{20}$

As to the prediction of inventions from technological progress, the evidence presented by Hornell Hart and others who have followed his lead may appear impressive and significant but it provides us with no useful formula for our specific problem. In reality, Hart and his followers have never attempted to measure inventions. Hart is merely trying to establish the thesis that man's technological and cultural progress has been accelerated over time. Specifically, archeological and historical information show relatively little change in technology in early times but a progressive acceleration of change in recent times, and every indication that this acceleration is continuing. For instance, in considering the rise of maximum speeds Hart points out that from the beginning of man until about 1700 B.C. man's fastest mode of locomotion was by means of his own two feet. At that date the horse made

${ }^{18}$ Gilfillan, op. cit.

${ }^{19}$ The highest coefficients of determination thus obtained were of the order of 0.09 to 0.16 . If one took into consideration the sampling errors, the predictive value of these relationships would be nil.

20 "Technical Change and Patent Statistics," Conference on Quantitative Description of Technological Change, sponsored by the Committees on Economic Growth and on Social Implications of Atomic Energy and Technological Change of the Social Science Research Council, 1951. 
its appearance in history and dominated the speed records until A.D. 1829, when the steam locomotive outstripped it. The pace of locomotives continued to increase but at a decelerating rate and by 1910 the speed record was taken by the automobile. Although the maximum speed of the automobile continued to increase, by 1921 the lead was lost to the airplane. It is taken for granted that the accelerated breaking of speed records in recent years is per se a measure of inventive activity.

Hart believes that in measuring the rate of technical change he is measuring the rate of invention but the student of inventions is interested primarily in the rate of the inventive process as such. An invention to him means a new configuration of objects and forces that will result in a new product or process to meet some human need; if not entirely new, it generally excels in quality, or in some other attribute, products or processes already known. The extent of its novelty, which might be described as the conceptual jump between the previously known and the new configuration, is the essence of what we may call the "amount of invention." We have devised no objective yardstick for the measurement of this quantity and may never be able to devise one.

In other words, Hornell Hart does not differentiate the elements which some students of invention have labeled innovation and diffusion, and other intermediaries, such as those which Gilfillan mentions, which contribute along with invention to the end process of technological or cultural progress. If we are ready to do without these conceptual distinctions between invention and the intervening processes connecting invention with technological progress, then we had better turn to the economists' concept of increased productivity. In increased productivity we have a more or less appropriate common denominator in terms of economic value, or market price of goods and services. With such a concept we should be able to compare and combine varying rates of change in different fields into some overall index of productivity. It must be realized, however, that in doing this we will have to abandon the narrower concept of invention, substituting in its place some measurable end product far removed from the initial act of inventing. It is quite possible, of course, that this may be the nearest we shall ever be able to come to measuring invention.

Perhaps we should illustrate how alien Hart's thinking is to our specific concept of inventive activity by citing one of the illustrations which he uses to demonstrate man's accelerating technological 
progress. After giving the following table which illustrates the accelerating rate with which life expectancy per decade has been increasing:

$\quad$ Dates
2000 B.C. to 200 B.C.
200 B.C. to A.D. 1840
1840 to 1910
1910 to 1940
1940 to 1955

Gains per Decade in Expectation at Birth

0.02

0.79

1.9

2.4

3.9

He proceeds to observe:

If increases in expectation of life at birth were to continue to accelerate along the trend indicated by the above figures, the average expectation of American babies born in the year 2000 would be approximately 100 years.

The increase in expectation of life has been grouped in this section as one of four examples of technological acceleration. .... ${ }^{21}$

It should be obvious to anyone that there is a wide gulf separating inventions that influence the longevity of man from their widespread adoption and use so that they affect significantly the life expectancy of large populations. Moreover, there are many external factors such as diet, mode of living, the organization and effectiveness of medical care, personal hygiene and cleanliness, and accidental hazards, to mention only the more important ones, which decidely influence life expectancy. But these considerations do not concern Hart. Following Ogburn, ${ }^{22}$ he takes it for granted that inventions are a recombination of different elements in the culture base, and that the rate of these recombinations depends on the number of elements available. As Hart puts it, "Inventions breed inventions."

We must conclude, of necessity, that this approach to measuring inventions is of little avail, at least now. It is possible that with appropriate analytical tools the time may come when we shall be able to do better in correlating at least major inventive periods with subsequent technological changes, as cause and effect. We certainly have not been able to do this so far to any significant degree.

It is conceivable that simultaneous analysis, in terms of input on the one hand and output as technological progress on the other, may

${ }^{21}$ Allen et al., op. cit., p. 34.

${ }^{28}$ William F. Ogburn, Social Change, 1922. 
prove more effective than either approach used by itself. This possibility has not been explored adequately. In any event, we need more reliable series to measure both input and output, and also a sharper crystallization of our concept of what it is that we are trying to measure, before much progress can be hoped for.

Of course, if one were ready to accept the theory of invention propounded by Ogburn there might be little reason to develop techniques, or more complete information, on input and output series for measuring inventions along the line which we have considered. According to Ogburn inventions are inevitable combinations of elements in the culture that are ripe to occur. If true, theoretically one should be able to develop a function, based on a properly conceived mathematical model, that could prognosticate the rate of new inventions at any point in time. However, Ogburn's theory of invention is far from validation. It fails completely to explain why some cultures prove much more dynamic than others, irrespective of the extent of the cultural base. It fails to account for plateaus that are frequent in the course of any art or even for an entire culture complex. It fails to consider the obvious fact that invention takes place in the mind of an individual; individual minds have not changed much, and the mind can encompass only a small fraction of the culture base in a culture such as ours. The strongest evidence in support of the cultural inevitability of inventions is the "frequent" occurrence of duplicate inventions more or less simultaneously. But, finding several hundred duplicates in literally millions of inventions, is hardly solid evidence for a theory, the postulates of which run counter to historical and much other evidence. ${ }^{23}$

If inventing is essentially not much more than the permutation and combination of the elements in the cultural base, as Ogburn and others have theorized, then how is one to account for the small number of persons who are inventors? Why has not the number and proportion of inventors increased with the expansion of the cultural base? More specifically, there are thousands of persons in positions where their advancement and prestige depends to a large extent on the patentable inventions which they are able to develop. According to the cultural

${ }^{23}$ I am not unaware of the contribution which my associate, Dr. Rossman, made to this line of evidence by pointing out the frequency of interference in the Patent Office as an indication of multiple inventions. It should be observed, however, that an interference does not necessarily mean duplicate inventions, but merely the fact that one or more claims of two or more patent applications overlap or are deemed to be the same. 
base theory of invention, with an expanding cultural base such inventors should be able to acquire larger and larger numbers of patents year after year. But that is not what happens. In fact, there is no evidence that the productivity of persons who are hired primarily to invent is greater today than some fifty or sixty years ago, notwithstanding the fact that the cultural base has expanded tremendously in the intervening period. ${ }^{24}$

The theory seems untenable to me. Therefore, I see little prospect of arriving at a solution to the problem via some theoretical formulation of the nature of inventions. On the contrary, I am of the belief that if there is a solution it can only come through empirical study of inventions, and related phenomena. Of special importance are studies focused on the acceleration and retardation of inventiveness, as we are able to infer these, however inadequately, from our analyses of inputs and outputs. If there is a solution to our problem, it can come only through intensive empirical studies. In such studies, series of patented inventions have a special role to play because of their ready availability.

We have already indicated that students of invention have often restricted themselves to the study of patented inventions. There are, as we have just mentioned, unquestionable advantages to such a limitation. In patents we have identifiable inventive acts which have met at least the minimum criteria of novelty and utility, the two prerequisites for a patentable invention. The question arises again: can we measure the rate of inventions in terms of patent statistics?

\section{Patents as a Basis for Measuring Inventive Activity}

In this century a number of students have attempted to use the number of patent applications or the annual number of patents issued as a possible measure of inventiveness, inventive activity, or other related concepts. The most persistent of this group has been Jacob Schmookler, who has argued at length and repeatedly that patent statistics are, in terms of the number of patents applied for, a useful measure of inventive activity. Schmookler has drawn many conclusions about inventive activity from patent data. Unfortunately, these conclusions

\footnotetext{
${ }^{24}$ The Patent Utilization Study of the Patent, Trademark, and Copyright Foundation of George Washington University includes analyses of information for the first time bearing on these and related problems of the productivity of inventors. This phase of the study has not been completed as yet.
} 
and assertions are not supported by valid empirical evidence, and in the opinion of this writer they are unwarranted and unsound..$^{25}$

It seems to me that in order for patent applications to serve as a useful index of inventive activity two conditions must be closely approximated: (1) The proportion of inventive activity resulting in patented inventions must have remained essentially invariant over the span of time during which patents are deemed to serve as a useful index; and (2) The input per average patent must have remained similarly invariant. Neither of these propositions can be established to be true and, indeed, what we know tends to negate them.

With respect to the first condition, we know that through the decades the ascendancy of different industries has shifted. Since the inclination of different industries in relation to patentable inventions varies widely it would be reasonable to assume that the proportion of inventive activity which has gone into patented inventions has not remained constant. In the 19th century most of the inventions were made by individuals, and an individual as a rule has no means of using his invention except by patenting it and selling it to someone who can exploit it. However, this is not the case with many corporations. Therefore the proportion of corporate inventive activity that goes into patented inventions is likely to differ from that of individual inventors.

Through the decades public attitudes and legal attitudes toward patent protection have oscillated; such shifts in all probability have influenced the economic value of patents and in turn the proportion of corporate and individual inventive activity going into patented inventions. ${ }^{26}$

The Patent Utilization Study shows that, at least in recent years, a large proportion of the assigned patented inventions that are put to

${ }^{25}$ In the original paper which I submitted to the Conference I documented my criticism of Schmookler by extensive quotations from his different published works. The publications committee of the conference has excised these pages. The Schmookler articles which were quoted from included: "The Interpretation of Patent Statistics," Journal of the Patent Office Society, February 1950, pp. 123-146; "Technical Change and Patent Statistics"; "The Utility of Patent Statistics," Journal of the Patent Office Society, June 1953, pp. 407-412; "Patent Application Statistics as an Index of Inventive Activity," Journal of the Patent Office Society, August 1953, p. 539; "The Level of Inventive Activity," Review of Economics and Statistics, May 1954, pp. 183-190.

${ }^{26}$ H. R. Meyers, "The United States Patent System in Historical Perspective," Patent, Trademark and Copyright Journal, Spring 1959, pp. 33-52. Daniel H. Kane, "Patentable Invention and Our Political Economy," Journal of the Patent Office Society, February 1950, pp. 89-96. Both these articles show that the attitude of the courts has shifted from time to time with respect to the upholding of litigated patent rights, and Meyers attributes this to shifts in public attitudes. 
use have been utilized before the patent application. Even if we assume that this practice is not new, at least it is pretty much confined to assigned inventions, which represented a small proportion of patents forty or fifty years ago. We have indicated in Table 2 the shift from individual inventors to hired inventors. Other things being equal, the practice of pre-application use of inventions would tend to reduce the proportion of inventions that are patented as a result of at least two factors.

1. Industrial use of an invention will bring out any limitations inherent in it, and if these are serious enough no patent application will be filed. This will tend to increase inventive activity which does not result in patented inventions in relation to inventive activity which gives rise to patents.

2. The patent laws of the United States prohibit the patenting of an invention if it has been in commercial use for more than twelve months. It is probable that some inventions which are put to use before patent application may inadvertently be used too long and thereby be disqualified. To the extent that this occurs, it again would increase the proportion of inventive activity which does not result in patent applications. It may be observed that early industrial use of an invention may also negatively influence the decision to pursue a patent application in instances where such use helps to make obsolete a device by stimulating substitute inventions of higher quality.

With the growing size of our markets, certain types of inventions can be exploited by hitting the market once. Inventions of this type which at one time would have been patented will not be patented today, thus reducing the ratio between inputs and the number of patented inventions.

Until recently the interval between a patent application and the granting of a patent was increasing, to the extent that this lag was reducing the economic value of some patents and it was exercising a depressing influence on applications. With growing hazards governing the outcome of patent litigation and the rising costs of such litigation some inventions which under more auspicious circumstances would have been patented, may not be patented. And as we have indicated the attitude of the courts has gone through several up and down cycles affecting the proportion of inventive activity going into patents.

The tradition of patenting has varied widely among different professional groups; as the relative importance of these groups has changed over time the proportion of inventions which are patented has 
changed in response. In companies which are narrowly specialized many inventions may not be patented because they fall outside of a given line. Many of the inventors who responded positively to the question as to whether they had had inventions which were not patented gave this as the reason why.

The growing share of government in research and development work and, to a lesser extent, the increased importance of other nonprofit agencies have radically shifted the patent yield from $R$ and $D$ expenditures. While on a large scale this influence may be comparatively recent, its roots go back to the establishment of land-grant colleges in 1870, and government financed agricultural research. There are undoubtedly additional factors which over the decades have altered the proportion of inventive activity that goes into inventions that are patented. And Schmookler's thesis has no basis if this is the case.

The second prerequisite if patents are to serve as a useful index of inventive activity is that input per average patentable invention be uniform. Here, again, the evidence tends to invalidate the assumption.

There is every reason to believe that the average input per patent has been markedly different for unassigned patents as compared with assigned patents. And since the proportion of assigned and unassigned patents has changed over time, the average input per patent has changed in all probability. Bearing on this, one of the facts on which information was sought in the Patent Utilization Study was the lapse of time from the moment when the invention was conceived to the moment when it was ready for patent application. The replies received show a very wide range. But the mean duration is about 9 months for inventors with assigned patents and over 20 months for inventors with unassigned patents. This disparity is corroborated by information of an entirely different nature reported by inventors of assigned and unassigned patents. The average number of patents held by inventors with unassigned patents in the sample was 9, for inventors with assigned patents this average number was $25 .^{27}$ These relationships could imply widely different inputs for patented inventions made by individual inventors in comparison to those made by employee inventors.

The National Science Foundation study of expenditures by industries for R and D shows wide differences in the amount spent in 1953 and 1954 in relation to the number of patents owned, or the number of patent applications filed. The range per patent application is from a low of about $\$ 11,000$ for petroleum products and extraction to a

\footnotetext{
${ }^{27}$ See Sanders, "Patent Utilization."
} 
high of about $\$ 24,000$ for professional and scientific instruments. The variations would be still wider if we considered corporations by size as well. With respect to expenditures per patent owned the range is from about $\$ 3,000$ for machinery to almost $\$ 8,000$ for chemicals and allied products. Here, too, the range would widen if corporation size was taken into consideration. These findings suggest marked variation in inputs per patent for different industries. It would be reasonable to assume that such differences have prevailed all along, and since the industrial origin of patents has varied widely over the decades, it would seem unreasonable to assume that the input per average patent has remained constant.

The changes in the types of inventions and in the education and training of inventors over the last century would lead one to infer that the quality of patented inventions has changed progressively, and such changes are also associated with changing inputs per patented invention or patent application.

If the Schmookler thesis on patent statistics were correct, it would follow that the probability of obtaining a patentable invention with a specified input has not changed. However, if the total volume of inventive activity increases sharply, the probability of multiple inventions based on the same idea (interference) will increase and obsolescence of inventions aborning will also increase. It would follow, therefore, that as inventive input increases, other things being equal, the number of patented inventions per unit of input will tend to diminish.

The Patent Utilization Study shows a marked increase in the proportion of patents with two or more inventors. The mean time lapse for these patents with two or more inventors is not significantly shorter than that reported by single inventors. Therefore the increased proportion of patents with multiple inventors (see footnote 16) would imply an'increase in the input per average patent.

These are only a few of the many factors that influence markedly the input-per-patent ratio and tend to nullify any fixed proportion between input and the number of patents. It seems futile to try to show gross relationships between input and patents, and patents and productivity without a penetrating study of the forces which have operated and are still operating on these variables. It requires sheer faith to maintain that a random sample of 1,000 patents in force in 1900 is equivalent to a similar sample of patents in force now in terms of inventive content, input, or any other factor of interest to social scientists. Moreover, without such comparability in units, it is difficult to see 
what significance to attach to the decline in the number of patent applications filed and the number of patents issued.

Another student of inventions who proposed to answer the question whether the number of patents might be used to measure inventiveness was Rupert Maclaurin. ${ }^{28}$ A pertinent observation of his was:

The problem of comparison is peculiarly difficult because the degree to which inventions are prolific at any given time depends in large measure on the state of the art in which the firm is working. For example, consider cases where there has been a major breakthrough in fundamental science, such as that which followed the work of Ampere, Von Helmholz, Maxwell, Faraday and others in laying the foundations of Electrical Revolution. Any firm operating on the crest of a technological revolution can be expected to produce a far larger number of new inventions than could be achieved by inventors of comparable intelligence working in an industry in which no such breakthrough had taken place. ${ }^{29}$

More specifically, on the question of whether patents measure invention, Maclaurin concluded:

This brings us to the question that is often raised as to whether the number of patents issued represents an effective measure of the inventive record. I believe that we have to answer this question negatively. Some measure can be obtained from getting a complete record of the patents issued to a particular firm or in a particular industry, and some rather crude comparisons can be made between firms and between industries on this record. There are, however, a number of serious weaknesses in any analysis based on this kind of statistical evidence. ${ }^{30}$

${ }^{28}$ Rupert W. Maclaurin, "The Sequence from Invention to Innovation, with Emphasis on Capital Supply and the Entrepreneur," Conference on the Quantitative Description of Technological Change, 1951.

${ }^{28} \mathrm{lbid}$., pp. 1-2.

I am inclined to account for the growth curve pattern of inventions in a given line thus: When there is a breakthrough, such as the one to which Maclaurin referred, many inventors flock to the new area, there is a period of building up, and the number of patents starts to increase. However, in spite of the increased manpower and resources, new inventions begin to require larger and larger inputs in the field and a decline finally sets in. As time goes on this decline is compounded because the supply of new inventions is becoming exhausted and no new inventors and resources are brought in; in fact some abandon the field in favor of greener pastures. This brings the cycle to a close.

${ }^{\text {so }}$ Ibid., p. 2. Emphasis added. 
I fully subscribe to the above views as to the relationship between patents and inventions. The weaknesses that Maclaurin went on to discuss are:

1. The distinction between fundamental research and engineering art. This is essentially the question we raised regarding the constancy of the proportion of inventions patented.

2. The distinction between basic patents and improvement patents. This is analogous to our consideration of the question of homogeneity of patents in a more specific and restricted sense.

3. The historical changes in the methods by which industrial companies apply for patents. In this connection Maclaurin cited the following:

For example, in the early days of the telephone industry, it was customary to pay inventors on the basis of the number of patents that they were granted during a year. This led to curious results. When some new problem demanded solution, a group of inventors in the company was brought together for a conference to discuss the broad objectives. They would then go off into their individual cells and produce as many possible answers to the problem as they could think of; in the final analysis, they would try to split up their inventions into a host of particular patents. This proved unsatisfactory for the company because such patents are much more difficult to sustain in the courts. The Telephone Company, preferring a general solution, abandoned its practice of giving inventors a premium for the number of patents taken out and changed its policy to offering bonuses for outstanding work. ${ }^{31}$

4. The different emphasis given to patents by companies equally interested in research. On this point his observation was as follows:

For example, a company which is patent-minded and anxious to develop a licensing position is much more likely to spend substantial sums on patent development; and while, of course, it is not possible to produce patents out of thin air, the presence of an able group of attorneys in a concern who are constantly on the

31 Ibid., pp. 3-4. 
alert for possible new inventions is much more likely to result in an "impressive" list of patents. ${ }^{32}$

\section{Summary and Conclusions}

In studies aiming to determine trends in inventing, an important prerequisite is a precise definition of what it is that one is trying to measure.

In view of the fact that, at least as of now, we know of no objective way to determine inventiveness directly it follows that our prospect of measuring it will have to depend on indirect methods. I have, therefore, examined and tried to appraise three different indirect approaches that have been employed to measure inventive activity.

Of the three approaches considered, the measurement of inventive activity by way of inventive input is perhaps the most direct and the most defensible logically. However, historically our available information regarding inputs is too incomplete and too inaccurate an index to be of much value at present. It is hoped that, with a sharper definition of what constitutes inventive activity and the extension and refinement of our information regarding inventive inputs, we may be able eventually to measure inventive activity from inputs with some degree of accuracy. But in all probability at no time can we hope to have a precise index of inventiveness or inventive activity.

The second approach, which also seems rational, at least in the abstract, is to measure inventiveness or inventive activity in terms of its outcome, technological advance. But the measurement of technological advance per se presents many practical problems. Therefore, it is difficult for me to see, for instance, how one can use the approach advocated by Hart to measure inventiveness. If the measurement of output proves a useful approach, it would seem to me it would have to be in terms of increased labor productivity as a result of inventiveness. But as we indicated, this would not be merely measuring inven-

${ }^{32}$ Ibid., p. 4.

The importance of the emphasis which a company places on patents, and the influence of this on patent productivity of its employees was brought to my attention very forcefully recently. A friend of mine, who is an electronics engineer, worked for a large corporation for over ten years engaged in research work on atomic reactors. This particular company works exclusively on government contracts, and has had no interest in patents. In the ten or more years during which my friend worked for this company he had two disclosures, one of these in collaboration with a colleague. Less than two years ago he transferred to another company, doing similar work, also on a government contract; this other company was not restricted to government contracts and emphasized patents in all its departments. During the first year of his employment for this company my friend had six disclosures. This illustrates how deceptive input could be as an index of patents, since eventually a certain proportion of these disclosures may end as patents. 
tiveness but also the speed of its adoption and the extent of its use. In other words, this would mean the abandonment of the conceptual purism of the rate of inventions per se, separate and distinct from innovation and the dissemination of its use (which some call imitation). But even in this restricted sense, our present-day measures of productivity are too crude and subject to too wide margins of errors to serve as a useful index of inventiveness.

Theoretically, it might be possible to reduce the margin of error in measuring inventiveness if the input and output approaches could be used simultaneously. It is believed that such a dual approach, if it could be evolved, would have compensatory factors in it so that errors would tend to offset one another; also inconsistencies between the input and output series might become apparent in cases where conflicting results were obtained.

The third method, that of using the number of patent applications or the number of patents issued as the index of inventive activity is least defensible, Its use by a number of students must be attributed to its ready availability. As I have tried to show there is no sound basis to assume that decade after decade the quality of patents has remained constant. Furthermore, there is no basis for assuming that inventive activity leading to patents has remained constant in relation to inventive activity in general, including that which gives rise to unpatentable inventions and those not patented for one reason or another.

In my opinion, none of the three approaches so far has demonstrated its effectiveness in measuring inventiveness or inventive activity. The conclusions arrived at by those who have followed more or less the approach which we have described as using inputs, though without too clear an appreciation of this fact, is that there has been an acceleration of inventiveness, though not in the sense in which Hart and his followers have claimed, i.e. following an exponential curve. Gilfillan does get a more or less straight line on a logarithmic grid, which would mean an exponential function, but the slopes of his graphs are decidedly more gentle than those described by Hart. As against these findings, if one considers the productivity of labor as the yardstick of inventiveness as distinct from inventive activity, the indication is that there has been no drastic change in trend, which has been on the whole upward but with a gentle slope of about 3 per cent per year. The preceding approaches all indicate increases though with markedly varying slopes. If one considers the number of patents as the criterion of increase or decrease in inventiveness, there has been a decline. Which of 
these four different courses comes nearest to describing the true rate and direction of change in inventions, including inventions that are patented, we cannot state with any degree of confidence. If I were to hazard a guess, I would be inclined to guess that inventiveness has increased perhaps paralleling roughly the increase in the productivity of labor as far as this country is concerned, though this would not be true for technologically backward countries. Inventive activity has increased more steeply in the United States than elsewhere though how steeply I would not attempt to define, since a considerable part of what is regarded as a measure of $R$ and $D$ is spurious rather than real.

Even though I question the utility of the patents count as an index of inventiveness, or inventive activity, I think that patents as verified inventive acts present a unique resource for study and understanding of the inventive process. A firsthand study of patented inventions should give the social scientist a unique opportunity to follow inventions and attempt to assess the social and economic impact that they have on our society. Study of patentees gives one an opportunity to study inventors, their characteristics, their method of work, influences which stimulate them and circumstances which tend to affect their productivity. It is somewhat surprising that, despite the lip service which many social scientists have given to the role of inventions and inventors in our lives, very little has been done by way of basic studies to understand the phenomenon of invention and the specific traits and characteristics of inventors. It would seem that for an understanding of inventive activity and its trends an intensive study of patents and inventors responsible for these patents should provide us with deeper insights for appraising changes in inventive trends. Yet when social scientists have become interested in patents, it has usually been in the readily available statistics of patent applications or patents issued; often the motive has been advocacy of changes in patent policies, on premises not always based on objectively verifiable facts. ${ }^{33}$ In other words, the contribution of social scientists to our understanding of inventiveness has so far added much to the heat of argumentation and very little to the light of understanding. A firsthand study of patents ought to help us to reverse this imbalance.

${ }^{33}$ In his scholarly work: "An Economic Review of the Patent System," Fritz Machlup after seventy-nine pages comes to this realistic conclusion: "No economist, on the basis of present knowledge, could possibly state with certainty that the patent system, as it now operates, confers a net benefit or a net loss upon society." Study of the Subcommittee on Patents, Trademarks, and Copyrights of the Committee on the Judiciary, United States Senate, 85th Congress, 2nd Session, Committee Print, 1958, p. 79. 


\section{COMMENT}

\section{JACOB SCHMOOKLER, University of Minnesota}

While it is not entirely clear just what Sanders means by invention, inventiveness, or inventive activity, in preferring direct measures of inventive input and output to patent statistics his logic is impeccable. No one will dispute that accurate measures of a thing are always better than an uncertain index of it. There is just one difficulty. While we have the uncertain index, we do not have accurate measures. What is more we cannot get them for years past which is the only period I have been concerned with. When such data as Sanders prefers are available, I shall be the first to abandon patent statistics in their favor. In the meantime, much as we might prefer caviar, we had better settle for plain bread when that is all we can get.

The question, therefore, is not whether to use statistics of aggregate patents granted or applied for, but how. Having discussed years ago ${ }^{1}$ other shortcomings of patent statistics as well as many of those to which Sanders now calls our attention, I cannot but agree with many of the items on his bill of particulars, and I welcome some of the new ones he has added to the list. The most important point to be made about the biases in the patent data is that except during the years since 1940, which I shall discuss later, their influence on the aggregate was probably slow-moving and gradual. Thus, it is probably correct that the propensity to patent differs among different industries, different occupations, etc. Hence, the ratio of the number of patents applied for in one period to the corresponding number in a period long before has no necessary relation to the relative amounts of inventive activity (however defined) in the two periods. Moreover, the relative importance of different industries and occupations changes considerably within business cycles. This suggests that year-to-year fluctuations in, say, total patent applications would also be difficult to interpret. I have recommended against the use of the data for such periods. ${ }^{2}$ On the other hand, and this is the important point, the relative importance of different industries and occupations does not change much from one business cycle to the next. Nor is the joint effect of other presumptive biases likely to be large from one business cycle to the next. Hence, it seems probable that a substantial difference between the

${ }^{1}$ Cf. my papers cited by Sanders.

${ }^{2}$ Cf. my "Patent Application Statistics as an Index of Inventive Activity," Journal of the Patent Office Society, August 1953, p. 550. 
number of patents applied for in, say, one five-year period and those in the next five years ordinarily represents a difference in the same direction in the volume of inventive activity.

In short, as I stated many years ago, "statistics of patents applied for by Americans are a useful indicator of fluctuations in American inventive activity for the period $1869-1938$, but . . . their utility as an index of secular trend cannot be assessed for want of suitable evidence. ${ }^{3}$ Nothing Sanders points out invalidates this position, and this is all I have ever contended on behalf of the aggregate data. As indicated, however, I sympathize with his unwillingness to use the data as an index of long-term trends. Of course, as we learn more about the characteristics of the aggregate data and ascertain which of the potential biases have substance, we may also be able to estimate the extent of each bias. In that case we may be able to adjust the data and use them to measure the trend, and perhaps even annual fluctuations.

In the meantime, however, we should realize that the biases are probably so strong in the post 1940 period that use of the data even as an index of intermediate period fluctuations in inventive activity in the last two decades is risky. The protracted war depleted the personnel of the Patent Office, the patent bar, and related private services. The proportion of direct, usually unpatented, government invention rose considerably. Even more important, large firms, and perhaps others to a lesser extent, curtailed their use of the patent system for a number of more or less related reasons. Chief among these were (1) a vigorous antitrust policy initiated in the late 1930's under which tens of thousands of patents held by large firms were thrown open to compulsory licensing, (2) the development of judicial attitudes casting doubt on the very patentability of ideas produced in corporate research and development programs, ${ }^{4}(3)$ the great growth of government-

3 "The Level of Inventive Activity," Review of Economics and Statistics, May 1954, p. 184. Italics in original.

4 The proportion of patents held invalid in infringement suits before U.S. Circuit Courts of Appeal ran to 70 per cent or higher from 1940 through 1957. Such a rate of invalidation is without parallel since $189 \mathrm{l}$ when these courts were established. Prior to 1891 the Supreme Court heard appeals concerning patents. During the heyday of agrarian unrest and antitrust agitation in the 1880's and 1890's, the high court also invalidated the great bulk of the patents on whose validity they passed. Cf. H. R. Mayers, "The United States Patent System in Historical Perspective," Patent, Trademark, and Copyright Journal, Spring 1959, Appendixes A and B esp. In the earlier years, of course, independent inventors were overwhelmingly the source of inventions, and whatever the legal hazards, they usually had to have patents to make much from their inventions. Hence, the high invalidation rate in the late nineteenth century probably had far less effect on patenting than now when many corporate managers usually consider patents rather unimportant anyway. 
financed corporate $\mathrm{R}$ and $\mathrm{D}$, accompanied generally by a government lien on the resulting product which usually diminished the incentive to patent, (4) the prolonged delays at the Patent Office in processing applications, and (5) a growing belief among corporate managers that a headstart usually provides all the protection the innovator either needs or can hope for, so that patents seemed less valuable than before. ${ }^{5}$ Presumably in consequence of those developments, while corporate $\mathrm{R}$ and $\mathrm{D}$ expenditures rose several-fold, patents taken out by firms increased by only one-fifth from 1940 to the mid-1950's.

Thus, after 1940 a number of factors diminish if they do not destroy the utility of the data as a reflection of inventive effort. Conceivably, however, certain segments of the data, e.g. patents by independents, may be used as an indication of those phases of inventive activity to which they relate; and further research may reveal bases for adjusting the balance.

The serviceability of the data for the pre-1940 period, however, is considerable, This is precisely the period for which data on $R$ and $D$ expenditures are poorest. More important, this period covers the development of the American economy from its "take-off" phase to "maturity". While the data suffer from real or presumptive biases of indeterminate magnitude, when used with care, skepticism, and imagination they can throw light on important aspects of economic growth which are unlikely to be illumined by any other means.

Their utility for this period can perhaps be best understood by means of an analogy. Suppose that for the period 1870 to 1940 we had no national income data. Could we then draw useful inferences about the course of national income over that period from statistics on railroad ton-miles of freight carried? The answer is, of course we could-even though we know that the proportion of the nation's freight carried by rail changed over the period, and even though we know that a ton-mile of freight may represent either a ton of sand carried one mile or a pound of gold carried two thousand miles. The case of patent statistics is entirely analogous.

I shall take time to discuss only two specific points which Sanders raises. The first of these concerns his contention that a rising average level of education of inventors indicates that the quality of inventive input has risen. When we say one inventor is better than another, we

\footnotetext{
${ }^{5}$ These developments will be discussed in my forthcoming "A Critique of Patent
} Statistics and a Review of the Literature" to which Kuznets referred. 
may mean that the inventions of the first are better than those of the second. And when we say that one invention is better than another, we mean either that one is economically more valuable than the other, or that it leads to more valuable later inventions than the other one does.

If this is what we mean, then it seems reasonable to assume that at any moment of time, the quality of inventive input in a given field varies, on the average, with the educational level of the inventors (although the degree of association between quality of product and education of the inventor would probably vary greatly among fields). This, I think, is the most we are entitled to affirm as plausible at this stage of our knowledge. For a very simple and compelling reason we cannot maintain that the well educated inventors in field $X$ today represent an input of a higher quality than either (1) the modestly educated inventors of field $X$ of yesterday, or (2) the modestly educated inventors of field $Y$ today. The reason is that the state of knowledge in $X$ today differs from that of $X$ yesterday or $Y$ today. Hence, the inventions in $X$ today may be inferior to those in $X$ yesterday or $Y$ today. Since this is true, how can we say, merely on the basis of educational at tainment, that the inventive input in $X$ today represents a higher quality than that in $X$ yesterday or $Y$ today?

Quite the contrary-for if we judge quality of input by value of output there are grounds for conjecturing that the rising educational level of inventors signifies a declining rather than a rising quality of inventive input. The growing complexity of science and technology demand an ever-higher educational preparation of those who would advance them further. The rising educational qualifications of inventors and the increase in group research may fundamentally represent an accommodation to the demands of a more complex state of knowledge, but there is no reason to suppose that this accommodation has exceeded the requirements of the situation, and it may well have fallen behind them.

On the other hand, if we define the quality of inventive input simply in terms of the creative power of the men involved, e.g. as measured by some hypothetical psychological test, then I know of no evidence which indicates that the better educated inventors of today possess this capacity in greater measure than did the less well educated inventors of yesterday. Here, too, it is conceivable that the drift of quality in this sense has been down, not up. 
My final comment concerns Sanders' comparisons between patents held or pending and corporate R and D expenditures. Sanders' statement that "the National Science Foundation Study found little, if any, association between the number of patent applications pending and the expenditures in 1953 and 1954 for $R$ and $D$ reported by different industries" is misleading. The NSF did not undertake to measure the association. In point of fact, the coefficient of correlation $(r)$ between patents pending and $R$ and $D$ expenditures reported by the NSF is 0.83 for the six industries, with the three size classes of firms in each, for which data are provided. ${ }^{6}$ Thus the correlation involves eighteen pairs. Since this coefficient means that 68 per cent of the variation in patents pending among the groups was associated with variation in $1953 \mathrm{R}$ and D outlays, it indicates that Sanders' statement on the subject is highly erroneous.

The coefficient is higher than I would have expected for a number of reasons. In the first place, I would have imagined that the great disturbances in patenting behavior, with their uneven incidence among industries and firms of different sizes, would have impaired the association more. In the second place, the great majority of the patents pending in one year are for inventions made in earlier years. In view of the turbulent changes in corporate $\mathrm{R}$ and $\mathrm{D}$ activity which occurred during the Korean war, the normal association between patents pending and the $\mathrm{R}$ and $\mathrm{D}$ activity of a given year would be reduced. Finally, as indicated in my comments on Simon Kuznets' paper, a good deal of corporate $\mathrm{R}$ and $\mathrm{D}$ activity is not directly, or even indirectly in many cases, devoted to inventive activity as defined by Kuznets, i.e. to the production of patentable invention. However we wish to define inventive activity, it is expenditures on inventive activity in the Kuznetsian sense which one would expect to find associated closely with patents. Corporate $\mathrm{R}$ and $\mathrm{D}$ activity includes scientific research per se at one extreme and engineering development at the other. The production of patentable inventions begins toward the close of what the NSF calls applied research and terminates some time after the beginning of what it defines as development. The wide variations between industries and between firms of different sizes in the relative proportions of what the NSF defines as basic research, applied research, and develop-

${ }^{8}$ The original data appear in Science and Engineering in American Industry: Final Report on a 1953-1954 Survey, National Science Foundation 56-16, Washington, 1956, Tables A-34 and A-35.

The coefficient of rank correlation between these variables, Spearman's rho, is $\mathbf{0 . 8 0}$. 
ment $^{7}$ and the existing uncertainty as to the precise location of pure inventive activity alone provide grounds for anticipating a less than perfect association between the output of patentable inventions and aggregate $\mathrm{R}$ and $\mathrm{D}$ expenditure.

In view of these considerations, a coefficient of correlation of .83 between the number of patents pending in 1953 and the $1953 \mathrm{R}$ and $\mathrm{D}$ outlays of eighteen groups of firms suggests that it is quite reasonable to use the total number of patent applications as an indicator of fluctuations in inventive activity-especially for periods of intermediate duration in the years before 1940 when the correlation was in all probability higher.

\section{COMMENT}

\section{S. Colum Gilfillan}

All the economists at this conference seem to agree that an index of inventive output, i.e., successful invention, is much needed but impossible to obtain. Not knowing it was impossible I prepared one, together with subtotals for a dozen measures of inventive input, most of which go back to 1880 , an unusually early date. For my measure of output I took the number of articles and books by Americans abstracted yearly in such indexes as Chemical Abstracts and Engineering Index, and for input, the number of engineers, chemists, and physicists in the principal societies and in training (lagged), and the professional grade staffs in organized $\mathrm{R}$ and $\mathrm{D}$, combining them with suitable weights. As shown in chart 1 , the curves, with one minor exception, are strikingly similar; steep and straight on the ratio scale. The combined inputs increased 226-fold in 1880-1955, but output 86-fold, suggesting the diminishing returns which Machlup and Kuznets expected. Patents to Americans went up but $2 \frac{1}{2}$ times, showing that they are quite worthless for long-time measurement of invention, although they might perhaps be used for consideration of shorttime peaks, with more caution than Schmookler has used. As for counts from lists of "important inventions", which Schmookler trusts less, they are still farther from true measures, registering virtually no

'Thus, in 1956 basic research varied from 1.7 per cent of total $R$ and $D$ expenditures in "other manufacturing industries" to 10.7 per cent in chemicals. Applied research varied from 8.0 per cent in the aircraft industry to 41.7 per cent in chemicals, and development varied from 90.0 per cent in the former to 47.6 per cent in the latter. Science and Engineering in American Industry: Report on a 1956 Survey, National Science Foundation 59-50, Washington, 1959, Appendix Table A-6. 


\section{CHART 1}

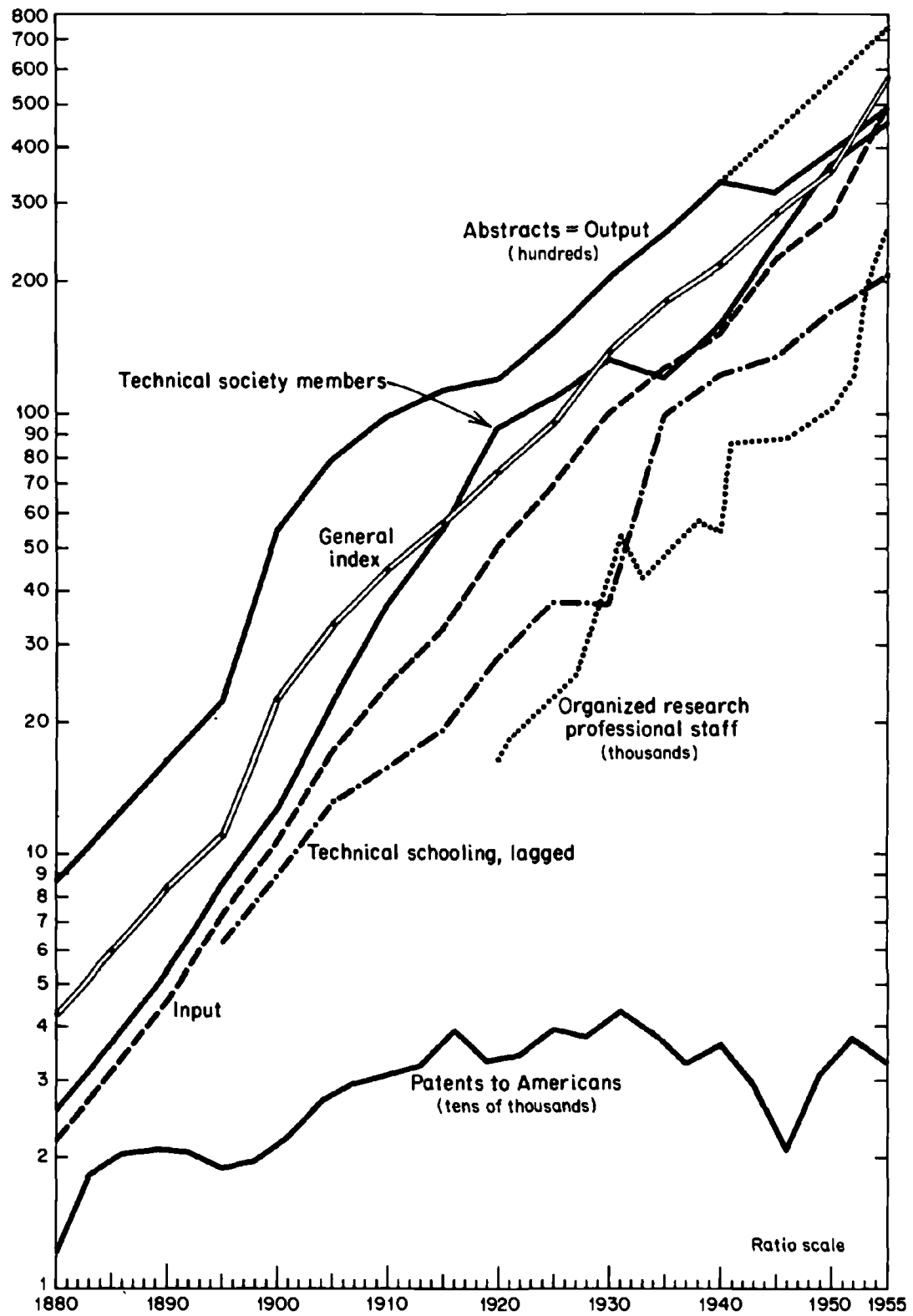

Subtotals and General Indexes on American Inventing and InventionOriented Research, 1880-1955 
progress at all. To Sanders' objection that the abstracts are often duplicative, I would reply that this might be an advantage, meeting the demand others have expressed at this conference for a way to distinguish or properly weight the important as opposed to the trivial inventions, since the more important the more duplication of notices. My findings will be summarized in the summer issue of Technology and Culture, and published in full by the Senate Subcommittee on Patents, for whom I am writing a book on Invention and the Patent System.

\section{COMMENT on Sanders and Kuznets}

\section{Herman I. Liebling, National Science Foundation}

Inasmuch as references have been made by Barkev Sanders and Simon Kuznets to the National Science Foundation series on total national research and development expenditures, I should like to cover several points concerning these statistics. I will limit my comments to these particular aspects, leaving for another occasion the more general problems of measuring inputs and outputs of scientific endeavors, also considered in these two papers, and in which we are deeply engaged.

Referring to expenditure series on research and development as camouflage for unresolved difficulties in measuring inputs into inventive activity, Sanders appears to direct his fire at series preceding those of the Foundation, although it would seem that any such series logically comprises a target for his criticism. Thus, while he suggests as a limitation that "the National Science Foundation statistics on research and development do not go very far back," his underlying substantive complaint is that "they are patently incomplete since they do not attempt to include individual effort. . . ." This latter characteristic, of course, is a condition irrelevant to the period encompassed by the time series, and, indeed, his real concern is revealed by his criticism that the research and development expenditure series "does not take into consideration qualitative changes in capital and labor or shifts in the industries responsible for the expenditure reported."1 Basically, then, his criticism is of a conceptual nature; on the one hand it refers

NOTE: The opinions expressed here are the views and conclusions of the author, and do not necessarily represent official views.

${ }^{1}$ It should be noted that shifts in industry research and development expenditures in fact are reported by various NSF industry reports covering the years 1953-57 (NSF 56-16, NSF 59-60, and NSF 60-59). 
to the lack of homogeneity implicit in money measures of inputs, and on the other to the restriction of coverage to "corporate bodies and government."

These are fundamental conceptual criticisms of $\mathrm{R}$ and $\mathrm{D}$ money series, shared to some extent by Kuznets, and again discussed in connection with comments on the latter's paper. It may be noted now that expenditure measures which require surmounting a test of pure homogeneity in terms of quality of inputs would rule out from economic analysis not only measures of inputs into science but also, perhaps, nearly all measures of industry factors of production presently included in our widely utilized national income and expenditure figures. It does not seem necessary to defend these latter statistics; to the contrary, these expenditure series continue to be useful for a large variety of purposes, even in their "impure" state.

On statistical grounds, Sanders states that the estimates of the R and D monetary series "are subject to a wide margin of error," without distinguishing the several available series on these expenditures. Whatever deficiencies may characterize other $\mathbf{R}$ and D series, which Sanders states were constructed "retrospectively," the official NSF series from 1953-54 to 1959-60, widely publicized since its release in December 1959 , was not so constructed. On the contrary, the NSF series represents the results of comprehensive fact-finding surveys undertaken in four separate sectors of the economy, including government, industry, colleges and universities, and nonprofit institutions. In contrast with other work in this field, the Foundation figures are distinctive in employing uniform concepts and definitions in the measurement of research and development expenditures in the sectors noted above, and have provided a substantial volume of integrated and detailed information on the breakdown of outlays by type of research, scientific field of effort, source of financing, etc., which satisfies widespread needs of private and public agencies and individuals. What Sanders states may have been applicable some years ago, but much has been done to remedy the situation in recent years.

Sanders states that the private industry sector data also are subject to a wide margin of error due to "many judgmental considerations" among different companies, although he does not give figures regarding the size of the error, as he does in the federal government sector. This is perhaps a safer course, but documentation of the extent of the error would have been desirable.

We in the Foundation would agree that the process of estimating 
research and development expenditures is fraught with difficulties; that many improvements in the technique will emerge as increased experience is gained with the surveys; and that revisions of estimates may become necessary, as they do in most statistical series of a complex nature. However, on the basis of our present experience with the surveys of industrial research and development, which have been conducted by at least two separate government agencies as well as by a private group, survey estimates of aggregate expenditures for overlap years have been satisfactorily close. Rather than giving cause for despair, the experience gained from the NSF surveys of industry R and $D$ expenditures has been increasingly revealing of the nature and scope of scientific efforts; and substantial grounds exist indicating that the surveys will continue to yield usable results along these lines. Of course, modification and improvement of concepts and procedures--which are constantly under study-may require changes in the future. Conferences such as these will benefit our deliberations on these matters.

We would agree with Sanders that a need for deflators of research and development expenditures exists to correct for changing purchasing power of research budgets, so that we may tear off the "money veil" disguising the course of real inputs into research and development. We agree that such a deflator needs to take into account the specific elements in such budgets, not only the personnel and equipment costs that he mentions, but also the expendable materials and supplies and indirect costs as well. A special purpose index of costs is indeed required for deflation; no sensible economist to our knowledge has recommended using the consumer price index for this purpose, as Sanders states. Toward this objective, efforts by the National Science Foundation are well under way to make available a special purpose deflator for research and development outlays. ${ }^{2}$

Turning now to the comments of Professor Kuznets on the research and development expenditure series, we proceed with the benefits of the accumulated wisdom he has provided in the pioneering work on concepts and methodology underlying the national income and product statistics. No modern economist may consider himself fully trained without exposure to the conceptual fundamentals of income and wealth measurements in which Kuznets has played such an important role. In this tradition, we shall ask that he apply no more

\footnotetext{
${ }^{2} \mathrm{We}$ are presently accelerating the work on deffation by enlisting under contract as a collection agency the forces of the U.S. Bureau of Labor Statistics.
} 
difficult criteria of measurement to the research and development series than have been applied to the national income and product statistics.

Kuznets notes accurately that the $\mathrm{R}$ and $\mathrm{D}$ expenditures series excludes efforts of individual and in dependent inventors, whether full or part time. In explanation, we note that in the construction of any complex set of statistics, attention must be given to its operational requirements in obtaining a successful measure, often requiring the adoption of certain conventions. These problems confronted the national income statisticians, who were compelled to make certain exclusions and omissions on these grounds. Thus, in the well-known example of housewives, their services contribute substantially to individual and national welfare, yet because the market place is not a test of their services, no actual or imputed value is given to their services in estimates of the national income. It is by now perhaps a hoary joke that if one marries one's housekeeper, the national income declines by the amount of her wages.

Other areas of difficult statistical measurement are excluded. Thus, by the same token if the "do-it-yourself" trend is as large as reported, the substantial omissions resulting from values created by the man who models or remodels his basement, who undertakes to supervise the construction of his home, etc., are missing from the national accounts. To proceed to other well-known areas, the production of "radio sets has its counterpart in the hobbies of the radio amateur, commercial shaves are akin to self-administered ones and the educational services of teachers often are supplemented by those of parents." 3

These matters are complicated by another distinction relating to the differentiation of work and play (of special relevance to individual inventors), which has been discussed at length in the substantial literature on national income theory in terms of inclusion as economic activity. Furthermore, part of this discussion refers to the restriction of the definition of economic activity to those things which require the use of scarce factors of production, according to which leisure-time and part-time invention or in fact any inventive activity for which no compensation is paid could be excluded. ${ }^{4}$ To cut across these problems and establish some type of operational requirements, the official national income statistics use an operational definition of economic

${ }^{3}$ U.S. Department of Commerce, National Income, A Supplement to the Survey of Current Business, Washington, 1958, p. 30.

4 Milton Gilbert and Irving B. Kravis, An International Comparison of National Products and the Purchasing Power of Currencies, Paris, 1954, p. 67. 
production those activities "reflected in the sales and purchase transactions of the market economy." 5 The concept of research and development expenditures used by NSF generally conforms to this definition, and efforts are under way to integrate them further into the national accounts. The point raised by Kuznets troubles us, but we see no easy solution. We find some comfort in the fact that the exclusion of these individuals appears more important historically than at present.

There is still another point on which Kuznets applies somewhat more rigorous standards to the research and development series than he does to the national income methodology we have learned from him. He is troubled that inputs measured in money do not accurately portray the true amount and quality of changes in the volume of inventive manhours. Changes in real wages paid to employed inventors may not portray a trend because "of the inability of firms to distinguish between the fertile inventive mind and the educated hack"- - major deficiency of the R and D series, according to Kuznets. This raises an important point concerning the special objective of Kuznets and that of the NSF series. Before approaching it, however, it should be noted that Kuznets himself adds that the defect he notes "is inherent in the money measure of input of any factor that cannot be effectively appraised by the market in terms of its quality or productivity." We agree that measurement of the productivity of inputs of research and development is difficult, just as the productivity of any skilled input or of physical capital continues to be troublesome in economic analysis. Thus, is he not applying a more rigorous test to research and development than to other inputs?

Kuznets has defined the concept of inventive activity to conform to his special need, excluding in the process activities associated with inventive activity by his usage. One must agree that each analyst is free to choose his particular definition to suit his particular purpose. Thereby, he excludes a large part if not nearly all that is called basic research, because this usually results in discovery rather than in invention, which he distinguishes by the test of practicality or usefulness. Development is also excluded because these activities concern application of the invention, not original invention.

As noted previously, Kuznets is entitled to use whatever definitions he finds useful. However, we believe (1) that relevant studies do not suggest that the type of personnel involved in the three phases of basic and applied research and development differ markedly, and (2) that

${ }^{5}$ National Income, p. 30. 
the three markets for scientists and engineers are competitive. On the contrary, the studies of supply and demand for scientists and engineers indicate that we are dealing with a mobile labor force, large sections of which are responsive to various economic supply and demand forces which result in redeployment of available scientific personnel in these three fields. Indeed, Fritz Machlup has argued that too many of our scientists have shifted from basic to applied research and development. ${ }^{6}$ Colleges and universities 'complain of the loss of scientific personnel to industrial activities in applied research and development and to military development work.

George B. Kistiakowsky, Science Advisor to President Eisenhower, recently noted that "many creative scientists have moved from the laboratory benches to the ranks of engineers. Fortunately, this has been a two-way flow. The engineers have undertaken to support basic scientific advances through the construction of great scientific instruments." "However, he does note also that the work, if not the personnel, of scientists is not the same as that of the engineer and that more basic scientific research is indispensable to technology.

Without going too deeply into the matter, it may be useful to indicate that the NSF series on R and D expenditures is designed to measure the scope of the scientific effort for government policy purposes. Against this perspective, we find useful measures which include components of basic and applied research and development.

Kuznets has written a challenging and stimulating paper. Not all the many issues he raises can be adequately discussed within the limited time available. There are a number of problems connected with his concepts of the measurement of inputs and outputs of scientific research in which we are interested and we believe that the publication resulting from the Conference proceedings will provide a vehicle for further studies.

'Fritz Machlup, "Can There Be Too Much Research ?' Science, November 28, 1958, pp. $1320-1325$.

${ }^{7}$ Excerpt from an address reproduced in Science News Letter, March 19, 1960, p. 187. 